\title{
Persistência dos efeitos da escarificação sobre a compactação de Nitossolo sob plantio direto em região subtropical úmida
}

\author{
Márcio Renato Nunes(1), Eloy Antonio Pauletto(1), José Eloir Denardin(2), Antonio Faganello(2), \\ Luiz Fernando Spinelli Pinto ${ }^{(1)}$ e Tiago Scheunemann ${ }^{(1)}$
}

\begin{abstract}
(1) Universidade Federal de Pelotas, Faculdade de Agronomia Eliseu Maciel, Departamento de Solos, Caixa Postal 354, CEP 96010-900 Pelotas, RS, Brasil. E-mail: marcio_r_nunes@yahoo.com.br, pauletto@ufpel.edu.br, Ifspin@ufpel.edu.br, tiago.scheunemann@hotmail.com (2)Embrapa Trigo, Caixa Postal 451, CEP 99001-970 Passo Fundo, RS, Brasil. E-mail: jose.denardin@embrapa.br, antonio.faganello@embrapa.br
\end{abstract}

Resumo - O objetivo deste trabalho foi avaliar a persistência dos efeitos da escarificação sobre a compactação de Nitossolo Vermelho, manejado sob plantio direto (PD), na região subtropical úmida do Brasil. O experimento foi realizado em blocos ao acaso, com quatro repetições e seis tratamentos, constituídos pelo tempo de manutenção do solo sob PD após escarificação: PD contínuo por 24 meses após escarificação, realizada em setembro de 2009; PD contínuo por 18 meses após escarificação, realizada em março de 2010; PD contínuo por 12 meses após escarificação, realizada em setembro de 2010; PD contínuo por seis meses após escarificação, realizada em março de 2011; plantio realizado em solo recém escarificado, em setembro de 2011; e PD contínuo e sem escarificação (testemunha). As espécies cultivadas na área foram: milho, safra 2009/2010; trigo, em 2010; soja, safra 2010/2011; centeio, em 2011; e milho, safra 2011/2012. Os efeitos dos tratamentos foram avaliados a partir de parâmetros físicos do solo e de parâmetros morfológicos e produtivos da cultura do milho, na safra 2011/2012. A escarificação do Nitossolo sob plantio direto, em região de clima subtropical úmido, não aumenta a produtividade de grãos de milho, e os seus efeitos sobre a estrutura do solo não persistem por mais de 18 meses.

Termos para indexação: Zea mays, atributos físicos do solo, compactação do solo, crescimento radicular, diâmetro do colmo, perfil cultural do solo.

\section{Persistence of chiseling effects on the compaction of a Nitisol under no-till in a humid subtropical region}

\begin{abstract}
The objective of this work was to evaluate the persistence of chiseling effects on the compaction of a Ferralic Nitisol (Rhodic), under no-till (NT), in the Brazilian humid subtropical region. The experiment was carried out in randomized complete blocks, with four replicates and six treatments, consisting of the time that the soil was kept under NT after chiseling: continuous NT for 24 months, after chiseling in September 2009; continuous NT for 18 months, after chiseling in March 2010; continuous NT for 12 months, after chiseling in September 2010; continuous NT for six months, after chiseling in March 2011; crop planted right after soil chiseling, in September 2011; and continuous NT, without chiseling (control). The species cultivated in the area were: corn in the 2009/2010 growing season; wheat in 2010; soybean in the 2010/2011 growing season; rye in 2011; and corn in the 2011/2012 growing season. Treatment effects were assessed by soil physical parameters and by morphological and productive parameters of the corn crop in the 2011/2012 growing season. The chiseling of Nitisol under no-till in a humid subtropical region does not increase corn grain yield, and its effects on soil structure do not last longer than 18 months.
\end{abstract}

Index terms: Zea mays, soil physical attributes, soil compaction, root growth, stalk diameter, soil cultural profile.

\section{Introdução}

Os preceitos da agricultura conservacionista que compõem o plantio direto compreendem: mobilização de solo apenas na linha ou na cova de semeadura; manutenção dos restos culturais na superfície do solo; diversificação de espécies pela rotação, pela sucessão ou pela consorciação de culturas; redução do intervalo de tempo entre colheita e semeadura; aporte de grande quantidade de material orgânico ao solo, com qualidade e frequência compatíveis com sua demanda biológica; e cobertura permanente do solo (Denardin et al., 2011). Entretanto, na região de clima subtropical úmido do Brasil, predomina a adoção de apenas dois desses 
preceitos: a mobilização restrita do solo e a manutenção de restos culturais em sua superfície, o que compromete a eficiência do sistema. A compactação do solo é uma consequência importante resultante dessa prática (Veiga et al., 2008; Reichert et al., 2009; Nunes et al., 2014).

A compactação do solo aumenta a resistência à penetração dos solos e diminui sua permeabilidade ao ar e à água (Veiga et al., 2008; Silva et al., 2009), o que pode levar à concentração das raízes na camada superficial do solo (Cavalieri et al., 2006; Secco et al., 2009), com reflexos negativos sobre o volume de solo explorado e a absorção de água e nutrientes pelas plantas (Secco et al., 2009). Na região de clima subtropical úmido do Brasil, safras agrícolas têm sido frustradas pela degradação associada a solos manejados sob plantio direto (Denardin et al., 2008), em razão do comprometimento do bom desenvolvimento do sistema radicular.

A escarificação vem sendo adotada para minimizar a compactação de solos manejados sob plantio direto (Camara \& Klein, 2005; Collares et al., 2008). Segundo esses autores, a técnica reduz a densidade do solo e a sua resistência à penetração, e aumenta a condutividade hidráulica e a taxa de infiltração de água. A persistência desses efeitos, porém, tem sido questionada (Prando et al., 2010; Silva et al., 2012), especialmente porque ainda são escassos os estudos com mais de um ano de duração que avaliem a persistência do efeito da escarificação sobre parâmetros de planta e atributos físicos do solo.

A escarificação do solo, no entanto, contrapõe-se aos preceitos do sistema plantio direto, pois envolve mobilização intensa de solo, maior tráfego de máquinas e de implementos agrícolas, além de maior custo de produção (Bertolini \& Gamero, 2010). Portanto, é importante que se avalie a persistência de seus efeitos em remediar restrições ao desenvolvimento radicular das plantas, em áreas sob plantio direto.

O objetivo deste trabalho foi avaliar a persistência do efeito da escarificação sobre a compactação de Nitossolo Vermelho, manejado sob plantio direto, na região subtropical úmida do Brasil.

\section{Material e Métodos}

O estudo foi realizado no campo experimental da Embrapa Trigo, em Passo Fundo, RS (2811'20"S, $52^{\circ} 19^{\prime} 62^{\prime \prime} \mathrm{W}$, a $691 \mathrm{~m}$ de altitude), em Nitossolo Vermelho distrófico latossólico (Santos et al., 2013), de textura argilosa e relevo suavemente ondulado. O clima, conforme a classificação de Köppen, é do tipo Cfa, subtropical úmido. A caracterização física do solo da área experimental está descrita na Tabela 1.

A área experimental vinha sendo conduzida sob plantio direto há dez anos, em sistema de produção que compreendia a sucessão das culturas: soja (Glycine max L.), no verão, e trigo (Triticum aestivum L.) no inverno. O solo da área apresentava evidente compactação na camada entre 0,07 e $0,20 \mathrm{~m}$ de profundidade, conforme avaliação expedita realizada em campo pelo método do perfil cultural, com abertura de trincheira até $0,3 \mathrm{~m}$ de profundidade e auxílio de penetrômetro de bolso.

$\mathrm{O}$ experimento foi instalado em setembro de 2009, em blocos ao acaso, com quatro repetições e seis tratamentos, em unidades experimentais com $43,2 \mathrm{~m}^{2}(8 \times 5,54 \mathrm{~m})$. Os tratamentos consistiram do tempo de manutenção do solo sob plantio direto, após a operação de escarificação: E24, plantio direto contínuo por 24 meses, após a escarificação realizada em setembro de 2009; E18, plantio direto contínuo por 18 meses, após a escarificação realizada em março de 2010; E12, plantio direto contínuo por 12 meses, após a escarificação realizada em setembro de 2010; E6, plantio direto contínuo por seis meses, após a escarificação realizada em março de 2011; E0, plantio realizado em solo recém escarificado, em setembro de 2011; e PD, solo com plantio direto contínuo e sem escarificação (testemunha). O efeito dos tratamentos foi avaliado ao longo da safra 2011/2012, na cultura do milho semeada em setembro de 2011.

As espécies cultivadas ao longo do período de condução do experimento foram: milho, safra 2009/2010; trigo, em 2010; soja, safra 2010/2011; centeio (Secale cereale L.), em 2011; e milho, safra 2011/2012 (Tabela 2).

As escarificações foram realizadas a $0,25 \mathrm{~m}$ de profundidade, com escarificador equipado com cinco hastes, espaçadas em $0,30 \mathrm{~m}$, e rolo destorroador, que dispensa a operação de gradagem subsequente. A operação foi realizada quando o solo encontravase com teor de umidade próximo ao do ponto de friabilidade.

O diâmetro de colmo e o sistema radicular das plantas foram avaliados, em dezembro de 2011, no estádio fenológico R3 da cultura do milho. O diâmetro de colmo foi avaliado aleatoriamente no segundo entrenó acima 
do solo, em dez plantas posicionadas na linha central de cada unidade experimental. O sistema radicular foi avaliado mediante a técnica da placa de pregos (Böhm, 1979). A placa de pregos empregada media $0,60 \mathrm{~m}$ de largura, $0,30 \mathrm{~m}$ de altura e $0,05 \mathrm{~m}$ de espessura. Essas dimensões possibilitaram a coleta de monólito de solo de $9 \mathrm{dm}^{3}$, com raízes. Após a dispersão e a retirada do solo, o sistema radicular presente em cada monólito foi dividido em três camadas: 0,00 a $0,07 \mathrm{~m} ; 0,07$ a $0,17 \mathrm{~m}$; e 0,17 a $0,30 \mathrm{~m}$. As raízes de cada camada foram secas em estufa, a $65^{\circ} \mathrm{C}$, por 72 horas, e a massa de matéria seca foi avaliada em balança com precisão de $0,0001 \mathrm{~g}$. A densidade radicular, em quilograma de raiz por metro cúbico de solo, foi estimada pela razão entre a massa de matéria seca de raiz e o volume de solo de cada camada.

A produtividade de grãos de milho foi estimada a partir da colheita de espigas, em área de $2,4 \mathrm{~m}^{2}$, no centro de cada unidade experimental, e extrapolada para quilograma por hectare.

Após a colheita do milho, na safra 2011/2012, foram abertas trincheiras no tratamento controle (plantio

Tabela 1. Caracterização física do solo da área experimental.

\begin{tabular}{|c|c|c|c|c|c|}
\hline $\begin{array}{l}\text { Camada } \\
\text { (m) }\end{array}$ & Argila & Silte & $\begin{array}{l}\text { Areia } \\
g_{\left.\mathrm{kg}^{-1}\right)}\end{array}$ & Argila dispersa & $\begin{array}{c}\mathrm{Dp}^{(1)} \\
\left(\mathrm{g} \mathrm{cm}^{-3}\right)\end{array}$ \\
\hline $0,00-0,07$ & 587 & 203 & 210 & 316 & 2,67 \\
\hline $0,07-0,17$ & 601 & 193 & 206 & 397 & 2,72 \\
\hline $0,17-0,20$ & 604 & 194 & 202 & 408 & 2,74 \\
\hline $0,20-0,30$ & 630 & 188 & 182 & 425 & 2,74 \\
\hline
\end{tabular}

${ }^{(1)} \mathrm{Dp}$, densidade de partículas. direto sem escarificação) com $0,60 \mathrm{~m}$ de largura por $0,30 \mathrm{~m}$ de profundidade, no sentido transversal às linhas de semeadura, para descrição do perfil cultural do solo (Tavares Filho et al., 1999). Essa técnica permitiu identificar três camadas distintas de solo: camada L, de 0,00 a $0,07 \mathrm{~m}$, caracterizada por solo com estrutura granular, agregados de tamanho variado, porosidade visível a olho nu e elevada presença de raízes; camada $\mathrm{C} \Delta \mu$, de 0,07 a $0,20 \mathrm{~m}$, caracterizada por solo com estrutura maciça e adensada, com mínima porosidade visível a olho nu e com menor presença de raízes em comparação à camada $\mathrm{L}$; e camada $\mathrm{F} \Delta \mu$, de 0,20 a $0,30 \mathrm{~m}$, caracterizada por solo com estrutura mais colunar e fissurada (Figura 1). Em seguida, trincheiras similares foram abertas nos demais tratamentos para coleta de amostras de solo com estrutura preservada, com uso de cilindros de aço inox de $48 \mathrm{~mm}$ de diâmetro por $30 \mathrm{~mm}$ de altura. As amostras foram tiradas na linha de semeadura, tendo-se seguido a caracterização das camadas descritas para o tratamento testemunha, em quatro profundidades. Desse modo, as camadas amostradas foram: 0,00 a $0,07 \mathrm{~m} ; 0,07$ a $0,17 \mathrm{~m} ; 0,17$ a $0,20 \mathrm{~m}$; e 0,20 a $0,30 \mathrm{~m}$.

As amostras de solo foram utilizadas para determinar sua densidade, macroporosidade, porosidade total (Donagema et al., 2011), resistência à penetração, grau de compactação e água disponível. As amostras foram saturadas por capilaridade, equilibradas na mesa de tensão a $6 \mathrm{kPa}$ e nas câmaras de Richards a 10 e a $1.500 \mathrm{kPa}$, tendo-se registrado o teor de água no solo em cada tensão. A água disponível foi calculada pela diferença entre a umidade do solo na capacidade de

Tabela 2. Indicação dos tratamentos e das espécies cultivadas ao longo do período experimental.

\begin{tabular}{|c|c|c|c|c|c|}
\hline Tratamento $^{(1)}$ & $\begin{array}{c}\text { Verão } \\
2009 / 2010 \\
\end{array}$ & $\begin{array}{c}\text { Inverno } \\
2010 \\
\end{array}$ & $\begin{array}{c}\text { Verão } \\
2010 / 2011 \\
\end{array}$ & $\begin{array}{c}\text { Inverno } \\
2011 \\
\end{array}$ & $\begin{array}{c}\text { Verão } \\
2011 / 2012 \\
\end{array}$ \\
\hline Testemunha & $\begin{array}{c}\text { Plantio direto } \\
\text { Milho }\end{array}$ & $\begin{array}{c}\text { Plantio direto } \\
\text { Trigo }\end{array}$ & $\begin{array}{c}\text { Plantio direto } \\
\text { Soja }\end{array}$ & $\begin{array}{c}\text { Plantio direto } \\
\text { Centeio }\end{array}$ & $\begin{array}{c}\text { Plantio direto } \\
\text { Milho }\end{array}$ \\
\hline E24 & $\begin{array}{c}\text { Escarificação } \\
\text { Milho }\end{array}$ & $\begin{array}{c}\text { Plantio direto } \\
\text { Trigo }\end{array}$ & $\begin{array}{c}\text { Plantio direto } \\
\text { Soja }\end{array}$ & $\begin{array}{l}\text { Plantio direto } \\
\text { Centeio }\end{array}$ & $\begin{array}{c}\text { Plantio direto } \\
\text { Milho }\end{array}$ \\
\hline E18 & $\begin{array}{c}\text { Plantio direto } \\
\text { Milho }\end{array}$ & $\begin{array}{c}\text { Escarificação } \\
\text { Trigo }\end{array}$ & $\begin{array}{c}\text { Plantio direto } \\
\text { Soja }\end{array}$ & $\begin{array}{l}\text { Plantio direto } \\
\text { Centeio }\end{array}$ & $\begin{array}{c}\text { Plantio direto } \\
\text { Milho }\end{array}$ \\
\hline E12 & $\begin{array}{c}\text { Plantio direto } \\
\text { Milho }\end{array}$ & $\begin{array}{c}\text { Plantio direto } \\
\text { Trigo }\end{array}$ & $\begin{array}{c}\text { Escarificação } \\
\text { Soja }\end{array}$ & $\begin{array}{l}\text { Plantio Direto } \\
\text { Centeio }\end{array}$ & $\begin{array}{l}\text { Plantio direto } \\
\text { Milho }\end{array}$ \\
\hline E6 & $\begin{array}{c}\text { Plantio direto } \\
\text { Milho }\end{array}$ & $\begin{array}{c}\text { Plantio direto } \\
\text { Trigo }\end{array}$ & $\begin{array}{c}\text { Plantio direto } \\
\text { Soja }\end{array}$ & $\begin{array}{c}\text { Escarificação } \\
\text { Centeio }\end{array}$ & $\begin{array}{c}\text { Plantio direto } \\
\text { Milho }\end{array}$ \\
\hline E0 & $\begin{array}{c}\text { Plantio direto } \\
\text { Milho }\end{array}$ & $\begin{array}{l}\text { Plantio direto } \\
\text { Trigo }\end{array}$ & $\begin{array}{c}\text { Plantio direto } \\
\text { Soja }\end{array}$ & $\begin{array}{c}\text { Plantio direto } \\
\text { Centeio }\end{array}$ & $\begin{array}{c}\text { Escarificação } \\
\text { Milho }\end{array}$ \\
\hline
\end{tabular}

${ }^{(1)}$ Testemunha, plantio direto contínuo e sem escarificação; E24, plantio direto contínuo por 24 meses após a escarificação; E18, plantio direto contínuo por 18 meses após a escarificação; E12, plantio direto contínuo por 12 meses após a escarificação; E6, plantio direto contínuo por seis meses após a escarificação; E0, plantio direto em solo recém escarificado. 
campo (tensão de $10 \mathrm{kPa}$ ) e a no ponto de murcha permanente (tensão de $1.500 \mathrm{kPa}$ ).

A resistência do solo à penetração foi determinada com penetrômetro eletrônico de bancada, modelo MA 933 (Marconi Equipamentos para Laboratórios, Piracicaba, SP), dotado de variador eletrônico de velocidade, sistema de registro de dados e cone com semiângulo de $300^{\circ}$ e diâmetro de $3 \mathrm{~mm}$. A velocidade de penetração foi de $10 \mathrm{~mm} \mathrm{~min}^{-1}$. A resistência do solo à penetração foi determinada nas amostras mantidas à tensão de água de $10 \mathrm{kPa}$. Os valores obtidos em cada parcela foram utilizados para obtenção das médias dos tratamentos, tendo-se excluído as leituras dos $3 \mathrm{~mm}$ superiores e inferiores das camadas, e considerado, portanto, apenas as leituras auferidas nos $24 \mathrm{~mm}$ centrais de cada amostra.

$\mathrm{O}$ teste de compressão uniaxial foi realizado mediante a aplicação sequencial das pressões de 25,50 , $100,200,400,800$ e $1.600 \mathrm{kPa}$, nas amostras mantidas à tensão de $10 \mathrm{kPa}$. Em seguida, as amostras foram secas em estufa a $105^{\circ} \mathrm{C}$, por 24 horas, e a densidade do solo foi calculada. O grau de compactação do solo foi obtido a partir da seguinte expressão, de Reichert et al., 2009: GC $(\%)=($ Ds inicial/Ds referência $) 100$, em que GC é o grau de compactação do solo; Ds inicial é a densidade do solo no momento da coleta; e Ds

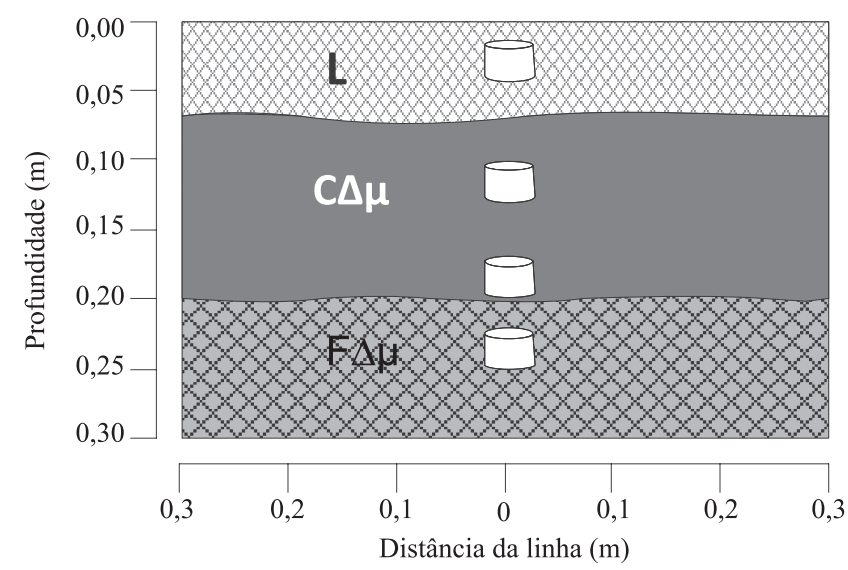

Figura 1. Perfil cultural de Nitossolo Vermelho distrófico latossólico, conduzido sob plantio direto contínuo, que indica a posição da coleta das amostras com estrutura preservada, em que: L, solo com estrutura granular, agregados de tamanho variados, porosidade visível a olho nu e elevada presença de raízes; $\mathrm{C} \Delta \mu$, solo com estrutura maciça e adensada, com mínima porosidade visível a olho nu e menor presença de raízes em comparação à camada $\mathrm{L}$; e F $\Delta \mu$, solo com estrutura típica de Nitossolo. referência é a densidade do solo após aplicação das pressões de 200, 400 e $800 \mathrm{kPa}$.

$\mathrm{O}$ efeito dos tratamentos sobre os atributos físicos do solo e os parâmetros de planta avaliados foi analisado por meio de análise de variância, e as médias foram comparadas pelo teste de Tukey, a 5\% de probabilidade. Os atributos físicos do solo foram analisados separadamente, em cada camada de solo.

\section{Resultados e Discussão}

A macroporosidade e a água disponível na camada compactada $(0,07$ a $0,20 \mathrm{~m})$ aumentaram imediatamente após a escarificação (E0), em comparação ao tratamento controle (plantio direto sem escarificação); ao passo que a densidade, a resistência à penetração e o grau de compactação do solo diminuíram significativamente (Tabela 3 e Figura 2). Esse efeito da escarificação na mitigação da compactação do solo também foi observado por Klein et al. (2008), Prando et al. (2010) e Silveira Junior et al. (2012). Entretanto, após 12 meses da escarificação (E12), as diferenças em relação à testemunha, na camada de 0,07 a 0,17, deixaram de ser significativas para os atributos resistência à penetração, macroporosidade e disponibilidade de água no solo. Para a densidade do solo e o grau de compactação, o efeito da escarificação deixou de ser significativo após 18 meses (E18) da escarificação.

$\mathrm{Na}$ camada 0,17 a $0,20 \mathrm{~m}$, os atributos água disponível e macroporosidade deixaram de diferir significativamente da testemunha já aos seis meses após a escarificação (E6), ao passo que, para densidade e grau de compactação do solo nessa camada, essa diferença nunca existiu (Tabela 3 e Figura 2). Desse modo, observa-se que os efeitos da escarificação do solo em profundidade mostraram-se mais efêmeros do que em superfície.

De acordo com Colonego \& Rosolem (2008, 2010), os efeitos da escarificação sobre as propriedades físicas do solo não persistem por mais de três anos. Esse efeito transitório da escarificação do solo sob plantio direto, na região subtropical úmida do Brasil, também foi mencionado por Da Rosa et al. (2008) e Silveira Junior et al. (2012) e, segundo os autores, está relacionado à ausência de cobertura adequada do solo, ao tipo de manejo adotado e ao regime de chuvas.

Em anos chuvosos, o solo tende a se reacomodar rapidamente, com menor persistência dos efeitos da escarificação (Nicoloso et al., 2008; Silva et al., 2012). 
Na região do Planalto Médio do Rio Grande do Sul, onde foi realizado o presente trabalho, a precipitação pluvial média chega a cerca de $1.800 \mathrm{~mm}$ anuais, distribuídos ao longo de todos os meses do ano (Nimer, 1989). Silva et al. (2012) afirmam que a efemeridade dos efeitos da escarificação está associada a ciclos de umedecimento e secagem do solo, que conferem certa resiliência aos atributos avaliados. É importante destacar, também, que o solo estudado continha aproximadamente $600 \mathrm{~g} \mathrm{~kg}^{-1}$ de argila (Tabela 1), e que solos argilosos retém mais água que os arenosos, o que os torna mais predispostos à compactação, mesmo após a escarificação (Silva et al., 2012).

As plantas que se desenvolveram no primeiro e no segundo cultivo após a escarificação apresentaram maior densidade radicular (Tabela 4), que passou de
$0,98 \mathrm{~kg} \mathrm{~m}^{-3}$, na testemunha, para 1,27 e $1,13 \mathrm{~kg} \mathrm{~m}^{-3}$ nos tratamentos E0 e E6, respectivamente. Na camada de 0,05 a $0,17 \mathrm{~m}$, que apresentou melhores condições físicas após a escarificação, os valores médios de densidade radicular passaram de $0,70 \mathrm{~kg} \mathrm{~m}^{-3}$ para $1,12 \mathrm{e}$ $0,98 \mathrm{~kg} \mathrm{~m}^{-3}$, nos tratamentos E0 e E6, respectivamente. Quanto ao diâmetro de colmo, os valores médios nos primeiros cultivos após a escarificação do solo (E0 e E6) também foram superiores aos observados na testemunha, apesar de não diferirem significativamente (Figura 3). Os efeitos da escarificação sobre a densidade de raízes também não foram duradouros e deixaram de ser significativos após 24 meses.

Contudo, o melhor desenvolvimento radicular e a tendência do engrossamento dos colmos indicam que a escarificação do solo possibilitou melhor

Tabela 3. Atributos físicos de Nitossolo Vermelho distrófico latossólico, de acordo com o tempo decorrido desde a escarificação do solo ${ }^{(1)}$.

\begin{tabular}{|c|c|c|c|c|c|c|c|}
\hline \multirow{2}{*}{$\begin{array}{l}\text { Camada } \\
(\mathrm{m})\end{array}$} & \multicolumn{6}{|c|}{ Tratamento $^{(2)}$} & \multirow{2}{*}{$\begin{array}{l}\mathrm{CV} \\
(\%)\end{array}$} \\
\hline & Testemunha & E0 & E6 & E12 & E18 & E24 & \\
\hline & \multicolumn{7}{|c|}{ Macroporosidade do solo $\left(\mathrm{m}^{3} \mathrm{~m}^{-3}\right)$} \\
\hline $0,00-0,07$ & $0,20 \mathrm{a}$ & $0,20 \mathrm{a}$ & $0,19 \mathrm{a}$ & $0,23 \mathrm{a}$ & $0,18 \mathrm{a}$ & $0,18 \mathrm{a}$ & 26,28 \\
\hline $0,07-0,17$ & $0,08 b$ & $0,15 \mathrm{a}$ & $0,15 \mathrm{a}$ & $0,14 \mathrm{ab}$ & $0,10 \mathrm{ab}$ & $0,10 \mathrm{ab}$ & 23,94 \\
\hline $0,17-0,20$ & $0,06 \mathrm{~b}$ & $0,12 \mathrm{a}$ & $0,08 \mathrm{ab}$ & $0,09 \mathrm{ab}$ & $0,06 \mathrm{~b}$ & $0,09 \mathrm{ab}$ & 30,30 \\
\hline \multirow[t]{2}{*}{$0,20-0,30$} & $0,06 \mathrm{~b}$ & $0,06 \mathrm{a}$ & $0,07 \mathrm{a}$ & $0,05 \mathrm{a}$ & $0,05 \mathrm{a}$ & $0,07 \mathrm{a}$ & 25,43 \\
\hline & \multicolumn{7}{|c|}{ Porosidade total do solo $\left(\mathrm{m}^{3} \mathrm{~m}^{-3}\right)$} \\
\hline $0,00-0,07$ & $0,59 \mathrm{a}$ & $0,56 \mathrm{a}$ & $0,56 \mathrm{a}$ & $0,57 \mathrm{a}$ & $0,55 \mathrm{a}$ & $0,57 \mathrm{a}$ & 7,61 \\
\hline $0,07-0,17$ & $0,48 \mathrm{a}$ & $0,52 \mathrm{a}$ & $0,51 \mathrm{a}$ & $0,50 \mathrm{a}$ & $0,49 \mathrm{a}$ & $0,52 \mathrm{a}$ & 9,37 \\
\hline $0,17-0,20$ & $0,46 \mathrm{a}$ & $0,50 \mathrm{a}$ & $0,48 \mathrm{a}$ & $0,48 \mathrm{a}$ & $0,46 \mathrm{a}$ & $0,47 \mathrm{a}$ & 3,54 \\
\hline \multirow[t]{2}{*}{$0,20-0,30$} & $0,48 \mathrm{a}$ & $0,48 \mathrm{a}$ & $0,50 \mathrm{a}$ & $0,49 \mathrm{a}$ & $0,48 \mathrm{a}$ & $0,48 \mathrm{a}$ & 0,05 \\
\hline & \multicolumn{7}{|c|}{ Densidade do solo $\left(\mathrm{g} \mathrm{cm}^{-3}\right)$} \\
\hline $0,00-0,07$ & $1,06 \mathrm{a}$ & $1,11 \mathrm{a}$ & $1,10 \mathrm{a}$ & $1,05 \mathrm{a}$ & $1,19 \mathrm{a}$ & $1,18 \mathrm{a}$ & 7,74 \\
\hline $0,07-0,17$ & $1,41 \mathrm{a}$ & $1,20 \mathrm{c}$ & $1,22 \mathrm{c}$ & $1,24 \mathrm{bc}$ & $1,34 \mathrm{ab}$ & $1,33 \mathrm{ab}$ & 3,12 \\
\hline $0,17-0,20$ & $1,43 \mathrm{a}$ & $1,33 \mathrm{a}$ & $1,34 \mathrm{a}$ & $1,35 \mathrm{a}$ & $1,40 \mathrm{a}$ & $1,35 \mathrm{a}$ & 4,61 \\
\hline \multirow[t]{2}{*}{$0,20-0,30$} & $1,36 \mathrm{a}$ & $1,34 \mathrm{a}$ & $1,28 \mathrm{a}$ & $1,35 \mathrm{a}$ & $1,35 \mathrm{a}$ & $1,35 \mathrm{a}$ & 4,15 \\
\hline & \multicolumn{7}{|c|}{ Resistência do solo à penetração (MPa) } \\
\hline $0,00-0,07$ & $0,97 \mathrm{a}$ & $1,06 a$ & $0,97 \mathrm{a}$ & $0,92 \mathrm{a}$ & $1,04 \mathrm{a}$ & $1,07 \mathrm{a}$ & 36,50 \\
\hline $0,07-0,17$ & $3,12 \mathrm{a}$ & $1,21 \mathrm{c}$ & $1,66 \mathrm{bc}$ & $1,89 \mathrm{abc}$ & $2,36 a b c$ & $2,84 \mathrm{ab}$ & 28,39 \\
\hline $0,17-0,20$ & $3,24 \mathrm{a}$ & $1,46 \mathrm{c}$ & $1,95 \mathrm{bc}$ & $3,29 \mathrm{a}$ & $3,16 \mathrm{ab}$ & $2,99 \mathrm{ab}$ & 20,98 \\
\hline \multirow[t]{2}{*}{$0,20-0,30$} & $2,65 \mathrm{a}$ & $2,36 \mathrm{a}$ & $2,31 \mathrm{a}$ & $2,65 \mathrm{a}$ & $3,19 \mathrm{a}$ & $2,81 \mathrm{a}$ & 10,05 \\
\hline & \multicolumn{7}{|c|}{ Água disponível $\left(\mathrm{m}^{3} \mathrm{~m}^{-3}\right)$} \\
\hline $0,00-0,07$ & $0,076 \mathrm{a}$ & $0,076 \mathrm{a}$ & $0,066 \mathrm{a}$ & $0,065 \mathrm{a}$ & $0,066 \mathrm{a}$ & $0,073 \mathrm{a}$ & 21,81 \\
\hline $0,07-0,17$ & $0,048 \mathrm{~b}$ & $0,063 \mathrm{a}$ & $0,059 \mathrm{a}$ & $0,050 \mathrm{~b}$ & $0,048 b$ & $0,055 \mathrm{~b}$ & 12,46 \\
\hline $0,17-0,20$ & $0,049 b$ & $0,065 \mathrm{a}$ & $0,057 \mathrm{ab}$ & $0,060 \mathrm{ab}$ & $0,055 b$ & $0,055 \mathrm{ab}$ & 14,35 \\
\hline $0,20-0,30$ & $0,064 \mathrm{a}$ & $0,064 a$ & $0,062 \mathrm{a}$ & $0,060 \mathrm{a}$ & $0,067 \mathrm{a}$ & $0,077 \mathrm{a}$ & 18,07 \\
\hline
\end{tabular}

${ }^{(1)}$ Médias seguidas por letras iguais, nas linhas, não diferem pelo teste de Tukey, a $5 \%$ de probabilidade. ${ }^{(2)}$ Testemunha, plantio direto contínuo e sem escarificação; E0, plantio direto em solo recém escarificado; E6, plantio direto contínuo por seis meses após a escarificação; E12, plantio direto contínuo por 12 meses após a escarificação; E18, plantio direto contínuo por 18 meses após a escarificação; E24, plantio direto contínuo por 24 meses após a escarificação. 
desenvolvimento das plantas nos primeiros cultivos subsequentes à operação. Corsini \& Ferraudo (1999) também observaram aumento do potencial de desenvolvimento radicular de milho, no primeiro ano agrícola após a escarificação. Da mesma forma, Prando et al. (2010) verificaram maior desenvolvimento radicular no primeiro ano, no solo escarificado, e que esse efeito não se manteve no segundo ano.
O maior desenvolvimento das raízes do milho, na primeira safra após a escarificação, não resultou em maior produtividade de grãos, tendo-se constatado até mesmo tendência contrária, no primeiro cultivo após a escarificação do solo (Figura 4). Para Secco et al. (2004), a escarificação anual ou a cada três anos não altera a produção de soja e milho em plantio direto. Klein \& Camara (2007) também relataram que a
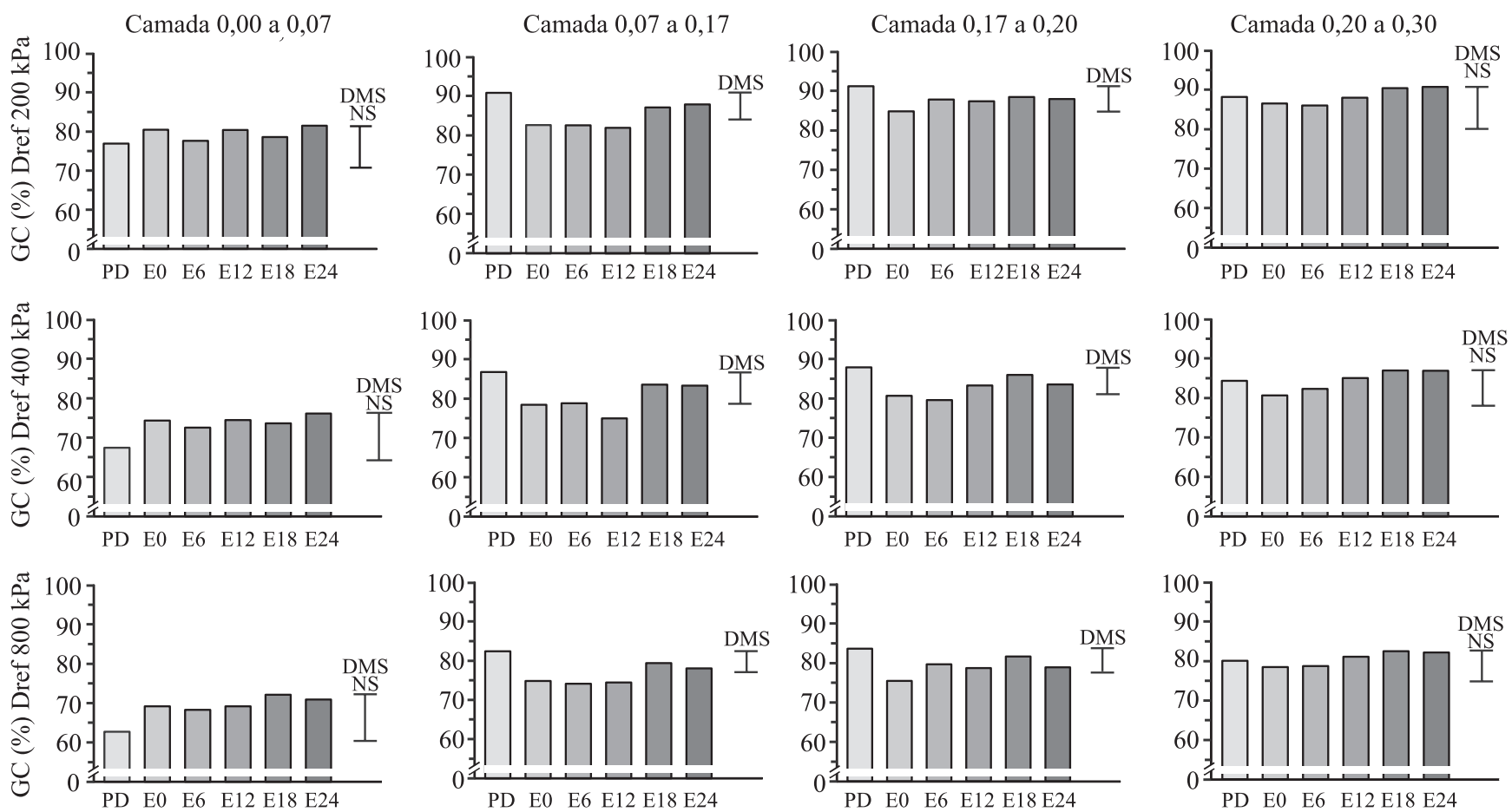

Figura 2. Grau de compactação de Nitossolo Vermelho distrófico latossólico em função da densidade referência (Dref) obtida após aplicação das pressões de $200 \mathrm{kPa}, 400 \mathrm{kPa}$ e $800 \mathrm{kPa}$. PD, plantio direto contínuo e sem escarificação; E0, plantio direto em solo recém escarificado; E6, plantio direto contínuo por seis meses após a escarificação; E12, plantio direto contínuo por 12 meses após a escarificação; E18, plantio direto contínuo por 18 meses após a escarificação; E24, plantio direto contínuo por 24 meses após a escarificação. DMS, diferença mínima significativa entre os tratamentos; e NS, diferença não significativa entre os tratamentos, pelo teste de Tukey, a 5\% de probabilidade.

Tabela 4. Densidade radicular de plantas de milho (Zea mays) cultivadas em Nitossolo Vermelho distrófico latossólico, de acordo com o tempo decorrido desde a escarificação do solo ${ }^{(1)}$.

\begin{tabular}{lccccccc}
\hline $\begin{array}{l}\text { Camada } \\
(\mathrm{m})\end{array}$ & Testemunha & E0 & E6 & E12 & E18 & E24 & $\begin{array}{c}\text { CV } \\
(\%)\end{array}$ \\
\hline $0,00-0,07$ & $--0,580 \mathrm{a}$ & $4,262 \mathrm{a}$ & $3,882 \mathrm{a}$ & $3,662 \mathrm{a}$ & $4,311 \mathrm{a}$ & $4,287 \mathrm{a}$ & 8,19 \\
$0,07-0,17$ & $0,700 \mathrm{c}$ & $1,120 \mathrm{a}$ & $0,980 \mathrm{ab}$ & $0,830 \mathrm{bc}$ & $0,710 \mathrm{c}$ & $0,710 \mathrm{c}$ & 7,92 \\
$0,17-0,20$ & $0,200 \mathrm{a}$ & $0,270 \mathrm{a}$ & $0,220 \mathrm{a}$ & $0,250 \mathrm{a}$ & $0,230 \mathrm{a}$ & $0,210 \mathrm{a}$ & 30,38 \\
\hline Total & $0,980 \mathrm{c}$ & $1,270 \mathrm{a}$ & $1,130 \mathrm{~b}$ & $1,040 \mathrm{bc}$ & $1,100 \mathrm{~b}$ & $1,070 \mathrm{bc}$ & 4,35 \\
\hline
\end{tabular}

(1) Médias seguidas por letras iguais, nas linhas, não diferem pelo teste de Tukey, a 5\% de probabilidade. Testemunha, plantio direto contínuo e sem escarificação; E0, plantio direto em solo recém escarificado; E6, plantio direto contínuo por seis meses após a escarificação; E12, plantio direto contínuo por 12 meses após a escarificação; E18, plantio direto contínuo por 18 meses após a escarificação; E24, plantio direto contínuo por 24 meses após a escarificação. 
escarificação de Latossolo Vermelho, embora melhore a condição física do solo, não aumenta o rendimento de soja em comparação ao obtido em solo não escarificado.

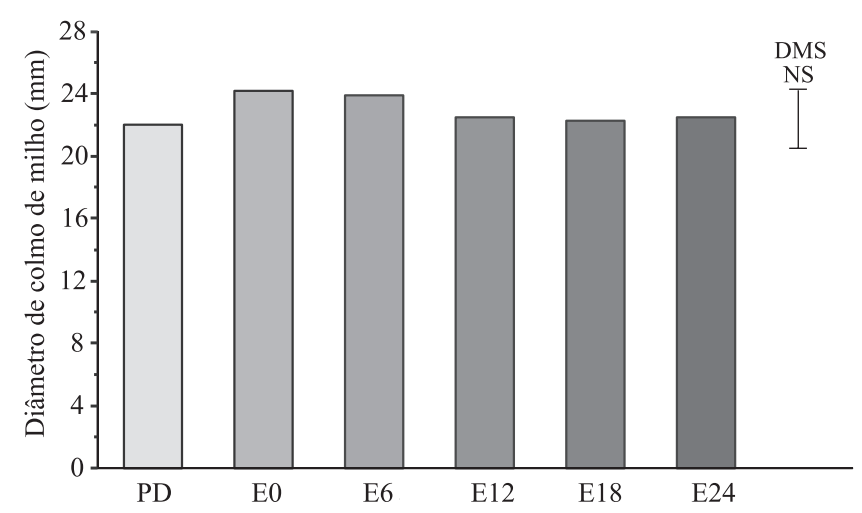

Figura 3. Diâmetro do colmo de plantas de milho (Zea mays) cultivadas em Nitossolo Vermelho distrófico latossólico, de acordo com os tratamentos: PD, plantio direto contínuo e sem escarificação; E0, plantio direto em solo recém escarificado; E6, plantio direto em solo escarificado há seis meses; E12, plantio direto em solo escarificado há 12 meses; E18, plantio direto em solo escarificado há 18 meses; E24, plantio direto em solo escarificado há 24 meses. DMS, diferença mínima significativa entre os tratamentos; e NS, diferença não significativa entre os tratamentos, pelo teste de Tukey, a 5\% de probabilidade.

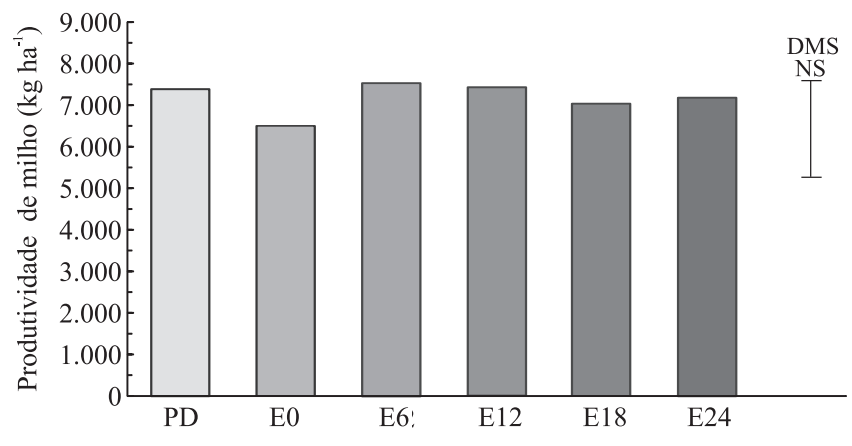

Figura 4. Produtividade de grãos de milho (Zea mays) cultivado em Nitossolo Vermelho distrófico latossólico, de acordo com os tratamentos: PD, plantio direto contínuo e sem escarificação; E0, plantio direto em solo recém escarificado; E6, plantio direto em solo escarificado há seis meses; E12, plantio direto em solo escarificado há 12 meses; E18, plantio direto em solo escarificado há 18 meses; E24, plantio direto em solo escarificado há 24 meses. DMS, diferença mínima significativa entre os tratamentos; e NS, diferença não significativa entre os tratamentos, pelo teste de Tukey, a 5\% de probabilidade.
No entanto, Secco et al. (2009) constataram que a escarificação aumenta o rendimento de grãos de milho e trigo em plantio direto, na comparação com o solo sob plantio direto sem escarificação. Klein et al. (2008) observaram que a escarificação em solo manejado há seis anos sob plantio direto aumentou o rendimento de grãos de trigo semeado sete meses após a escarificação. A divergência de resultados possivelmente deve-se ao fato de a produtividade das plantas não ser função apenas do solo, o que faz com que a melhor condição física do solo não resulte, necessariamente, em maior produtividade (Figura 4).

Collares et al. (2008) verificaram que a escarificação de Latossolo Vermelho manejado sob plantio direto favoreceu o crescimento radicular e aumentou a área foliar e a altura de plantas de feijão (Phaseolus vulgaris L.), mas não afetou a produtividade da cultura. Derpsch et al. (1986) observaram que o plantio direto de trigo e de soja é mais produtivo do que o cultivo mínimo (escarificação) com essas espécies. Conforme os autores, o plantio direto com uso de cultivos de cobertura em rotação é um sistema de produção eficiente em aumentar a produtividade das culturas.

Assim, ao se considerar os efeitos efêmeros da escarificação sobre parâmetros de planta e atributos físicos do solo, bem como a ausência de resposta produtiva do milho, percebe-se que a prática não se justifica.

\section{Conclusões}

1. A escarificação de Nitossolo sob plantio direto, em região de clima subtropical úmido do Brasil, não aumenta a produtividade de grãos de milho.

2. Os efeitos positivos da escarificação sobre os atributos físicos do solo e sobre o desenvolvimento radicular das plantas de milho não persistem por mais de 18 meses.

3. A escarificação do solo não proporciona melhoria efetiva e duradoura à estrutura de solos argilosos sob plantio direto, em região de clima subtropical úmido do Brasil.

\section{Agradecimentos}

À Coordenação de Aperfeiçoamento de Pessoal de Nível Superior (Capes), pela concessão de bolsa e à Embrapa Trigo, pelo apoio na condução do experimento de campo. 


\section{Referências}

BERTOLINI, E.V.; GAMERO, C.A. Demanda energética e produtividade da cultura do milho com adubação de présemeadura em dois sistemas de manejo do solo. Revista Energia na Agricultura, v.25, p.1-23, 2010.

BÖHM, W. Methods of studying root systems. New York: Springer-Verlag, 1979. DOI: 10.1007/978-3-642-67282-8.

CAMARA, R.K.; KLEIN, V.A. Escarificação em plantio direto como técnica de conservação do solo e da água. Revista Brasileira de Ciência do Solo, v.29, p.789-796, 2005. DOI: 10.1590/ S0100-06832005000500014.

CAVALIERI, K.M.V.; TORMENA, C.A.; VIDIGAL FILHO, P.S.; GONÇALVES, A.C.A.; COSTA, A.C.S. da. Efeitos de sistemas de preparo nas propriedades físicas de um Latossolo Vermelho distrófico. Revista Brasileira de Ciência do Solo, v.30, p.137-147, 2006. DOI: 10.1590/S0100-06832006000100014.

COLLARES, G.L.; REINERT, D.J.; REICHERT, J.M.; KAISER, D.R. Compactação de um Latossolo induzida pelo tráfego de máquinas e sua relação com o crescimento e produtividade de feijão e trigo. Revista Brasileira de Ciência do Solo, v.32, p.933-942, 2008. DOI: 10.1590/S0100-06832008000300003.

COLONEGO, J.C.; ROSOLEM, C.A. Estabilidade de agregados do solo após manejo com rotações de culturas e escarificação. Revista Brasileira de Ciência do Solo, v.32, p.1399-1407, 2008. DOI: $10.1590 / \mathrm{S} 0100-06832008000400004$.

COLONEGO, J.C.; ROSOLEM, C.A. Soybean root growth and yield in rotation with cover crops under chiseling and no-till. European Journal of Agronomy, v.33, p.242-249, 2010. DOI: 10.1016/j.eja.2010.06.002.

CORSINI, P.C.; FERRAUDO, A.S. Efeitos de sistemas de cultivo na densidade e macroporosidade do solo e no desenvolvimento radicular do milho em Latossolo Roxo. Pesquisa Agropecuária Brasileira, v.34, p.289-298, 1999. DOI: 10.1590/ S0100-204X1999000200017.

DA ROSA, D.P.; REICHERT, J.M.; SATTLER, A.; REINERT, D.J.; MENTGES, M.I.; VIEIRA, D.A. Relação entre solo e haste sulcadora de semeadora em Latossolo escarificado em diferentes épocas. Pesquisa Agropecuária Brasileira, v.43, p.395-400, 2008. DOI: 10.1590/S0100-204X2008000300015.

DENARDIN, J.E.; KOCHHANN, R.A.; BACALTCHUK, B.; SATTLER, A.; DENARDIN, N.D'A.; FAGANELLO, A.; WIETHÖLTER, S. Sistema plantio direto: fator de potencialidade da agricultura tropical brasileira. In: ALBUQUERQUE, A.C.S.; SILVA, A.G. (Ed.). Agricultura tropical: quatro décadas de inovações tecnológicas, institucionais e políticas. Brasília: Embrapa Informação Tecnológica, 2008. p.1251-1273.

DENARDIN, J.E.; KOCHHANN, R.A.; FAGANELLO, A. 15 de abril: dia nacional da conservação do solo: a agricultura desenvolvida no Brasil é conservacionista ou não? Boletim Informativo da Sociedade Brasileira de Ciência do Solo, v.36, p.10-15, 2011.

DERPSCH, R.; SIDIRAS, N.; ROTH, C.H. Results of studies made from 1977 to 1984 to control erosion by cover crops and no-tillage techniques in Paraná, Brazil. Soil and Tillage Research, v.8, p.253-263, 1986. DOI: 10.1016/0167-1987(86)90338-7.

DONAGEMA, G.K.; CAMPOS, D.V.B. de; CALDERANO, S.B.; TEIXEIRA, W.G.; VIANA, J.H.M. (Org.). Manual de métodos de análise de solos. 2.ed. rev. Rio de Janeiro: Embrapa Solos, 2011. 230p. (Embrapa Solos. Documentos, 132).

KLEIN, V.A.; CAMARA, R.K. Rendimento da soja e intervalo hídrico ótimo em Latossolo Vermelho sob plantio direto escarificado. Revista Brasileira de Ciência do Solo, v.31, p.221-227, 2007. DOI: 10.1590/S0100-06832007000200004.

KLEIN, V.A.; VIEIRA, M.L; DURIGON, F.F.; MASSING, J.P.; FÁVERO, F. Porosidade de aeração de um Latossolo Vermelho e rendimento de trigo em plantio direto escarificado. Ciência Rural, v.38, p.365-371, 2008. DOI: 10.1590/S0103-84782008000200011.

NICOLOSO, R. da S.; AMADO, T.J.C.; SCHNEIDER, S.; LANZANOVA, M.E.; GIRARDELLO, V.C.; BRAGAGNOLO, J. Eficiência da escarificação mecânica e biológica na melhoria dos atributos físicos de um Latossolo muito argiloso e no incremento do rendimento de soja. Revista Brasileira de Ciência do Solo, v.32, p.1723-1734, 2008. DOI: 10.1590/S0100-06832008000400037.

NIMER, E. Climatologia do Brasil. 2.ed. Rio de Janeiro: IBGE, 1989. 442p.

NUNES, M.R.; DENARDIN, J.E.; FAGANELO, A.; PAULETTO, E.A.; PINTO, L.F.S. Efeito de semeadora equipada com haste sulcadora para ação profunda em solo com plantio direto. Revista Brasileira de Ciência do Solo, v.38, p.627-638, 2014. DOI: 10.1590/S0100-06832014000200027.

PRANDO, M.B.; OLIBONE, D.; OLIBONE, A.P.E.; ROSOLEM, C.A. Infiltração de água no solo sob escarificação e rotação de culturas. Revista Brasileira de Ciência do Solo, v.34, p.693-700, 2010. DOI: 10.1590/S0100-06832010000300010.

REICHERT, J.M.; SUZUKI, L.E.A.S.; REINERT, D.J.; HORN, R.; HAKANSSON, I. Reference bulk density and critical degree-of-compactness for no-till crop production in subtropical highly weathered soils. Soil and Tillage Research, v.102, p.242-254, 2009. DOI: 10.1016/j.still.2008.07.002.

SANTOS, H.G. dos; JACOMINE, P.K.T.; ANJOS, L.H.C. dos; OLIVEIRA, V.A. de; LUMBRERAS, J.F.; COELHO, M.R.; ALMEIDA, J.A. de; CUNHA, T.J.F.; OLIVEIRA, J.B. de. Sistema brasileiro de classificação de solos. 3.ed. rev. e ampl. Brasília: Embrapa, 2013. 353p.

SECCO, D.; REINERT, D.J.; REICHERT, J.M.; SILVA, V.R. da. Atributos físicos e rendimento de grãos de trigo, soja e milho em dois Latossolos compactados e escarificados. Ciência Rural, v.39, p.58-64, 2009. DOI: 10.1590/S0103-84782009000100010.

SECCO, D.; REINERT, D.R.; REICHERT, J.M.; ROS, C.O. da. Produtividade de soja e propriedades físicas de um Latossolo submetido a sistemas de manejo e compactação. Revista Brasileira de Ciência do Solo, v.28, p.797-804, 2004. DOI: 10.1590/ S0100-06832004000500001.

SILVA, S.G.C.; SILVA, A.P. da; GIAROLA, N.F.B.; TORMENA, C.A.; SÁ, J.C.M. Temporary effect of chiseling on the compaction of a Rhodic Hapludox under no-tillage. Revista Brasileira 
de Ciência do Solo, v.36, p.547-555, 2012. DOI: 10.1590/ S0100-06832012000200024.

SILVA, V.R. da; REICHERT, J.M.; REINERT, D.J.; BORTOLUZZI, E.C. Soil water dynamics related to the degree of compaction of two Brazilian oxisols under no-tillage. Revista Brasileira de Ciência do Solo, v.33, p.1097-1104, 2009. DOI: 10.1590/ S0100-06832009000500003.

SILVEIRA JUNIOR, S.D. da; SILVA, A.P. da; FIGUEIREDO, G.C.; TORMENA, C.A.; GIAROLA, N.F.B. Qualidade física de um Latossolo Vermelho sob plantio direto submetido à descompactação mecânica e biológica. Revista Brasileira de Ciência do Solo, v.36, p.1854-1867, 2012. DOI: 10.1590/ S0100-06832012000600020.

TAVARES FILHO, J.; RALISCH, R.; GUIMARÃES, M.F.; MEDINA, C.C.; BALBINO, L.C.; NEVES, C.S.V.J. Método do perfil cultural para avaliação do estado físico de solos em condições tropicais. Revista Brasileira de Ciência do Solo, v.23, p.393-99, 1999.

VEIGA, M. da; REINERT, D.J.; REICHERT, J.M.; KAISER, D.R. Short and long-term effects of tillage systems and nutrient sources on soil physical properties of a Southern Brazilian Hapludox. Revista Brasileira de Ciência do Solo, v.32, p.1437-1446, 2008. DOI: $10.1590 / \mathrm{S} 0100-06832008000400008$.

Recebido em 28 de abril de 2014 e aprovado em 10 de julho de 2014 